\title{
DP -602
}

Chemical Separations Processes for Plutonium and Uranium

AEC Research and Development Report

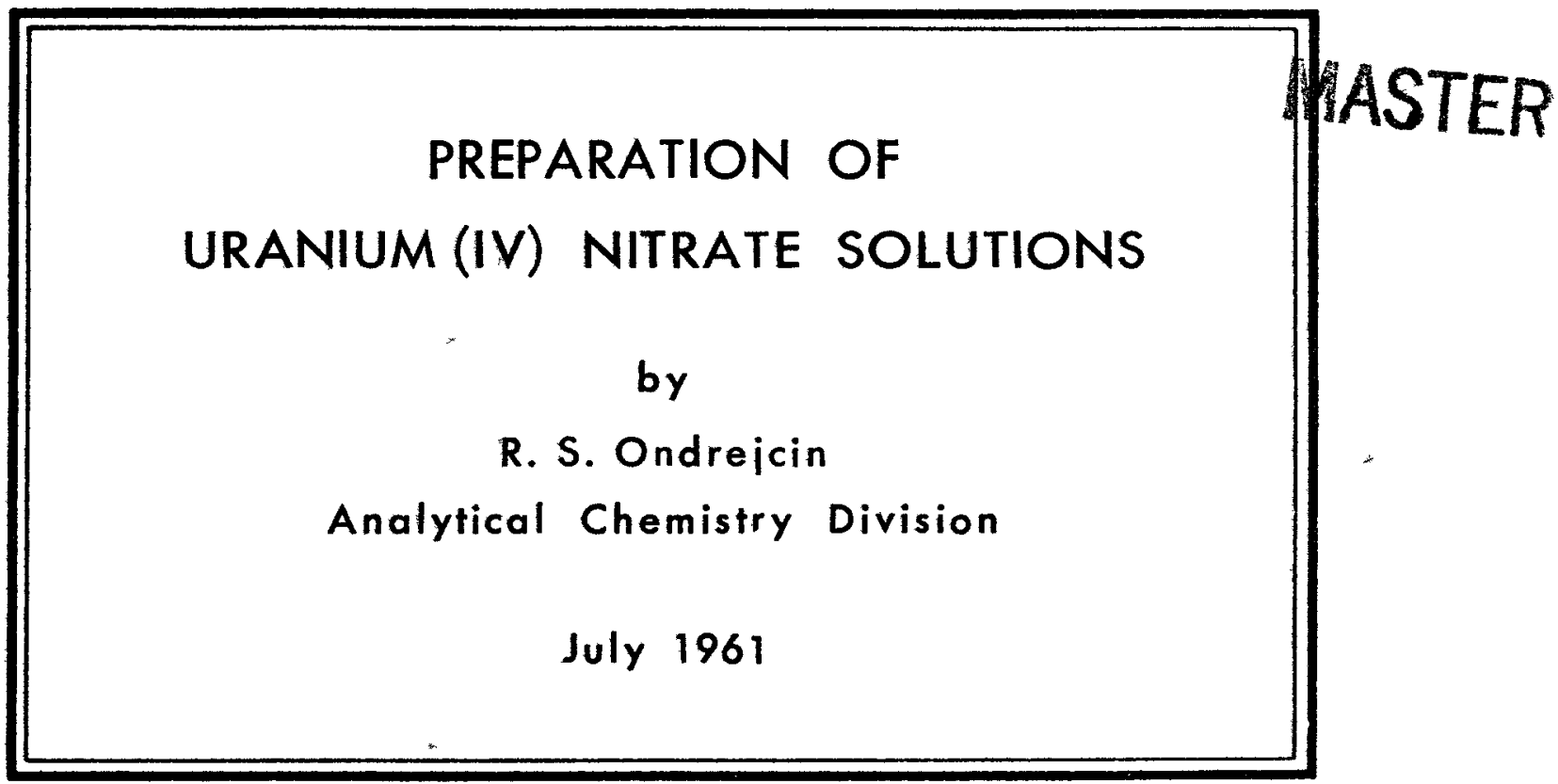

E. I. du Pont de Nemours \& Co.

Savannah River Laboratory

Aiken, South Carolina 


\section{DISCLAIMER}

This report was prepared as an account of work sponsored by an agency of the United States Government. Neither the United States Government nor any agency Thereof, nor any of their employees, makes any warranty, express or implied, or assumes any legal liability or responsibility for the accuracy, completeness, or usefulness of any information, apparatus, product, or process disclosed, or represents that its use would not infringe privately owned rights. Reference herein to any specific commercial product, process, or service by trade name, trademark, manufacturer, or otherwise does not necessarily constitute or imply its endorsement, recommendation, or favoring by the United States Government or any agency thereof. The views and opinions of authors expressed herein do not necessarily state or reflect those of the United States Government or any agency thereof. 


\section{DISCLAIMER}

Portions of this document may be illegible in electronic image products. Images are produced from the best available original document. 


$$
D P-602
$$

CHEMICAL SEPARATIONS PROCESSES

FOR PLUTONIUM AND URANIUM

(TID-4500, 16th Ed.)

\section{PREPARATION OF URANIUM (IV) NITRATE SOLUTIONS}

by

Robert S. Ondrejcin

July 1961

E. I. du Pont de Nemours \& Co.

Explosives Department - Atomic Energy Division

Technical Division - Savannah River Laboratory

Printed for

The United States Atomic Energy Commission

Contract AT(07-2)-1

Approved by

H. M. Kelley, Research Manager

Analytical Chemistry Division 


\begin{abstract}
A simple procedure was developed for the preparation of uranium(IV) nitrate solutions in dilute nitric acid. Zinc metal was used as a reducing agent for uranium(VI) in dilute sulfuric acid. The uranium(IV) was precipitated as the hydrated oxide and dissolved in nitric acid. Uranium(IV) nitrate solutions were prepared at a maximum concentration of $100 \mathrm{~g} / 1$. The uranium(VI) content was less than $2 \%$ of the $\operatorname{uranium}(I V)$.
\end{abstract}




\section{CONTENTS}

$\begin{array}{lr} & \frac{\text { Page }}{\text { Introduction }} \\ \text { Summary } & 4 \\ \text { Discussion } & 5 \\ \text { Reduction } & 5 \\ \text { Separation } & 5 \\ \text { Stability of Solutions } & 7 \\ \text { Bibliography } & 7\end{array}$

\section{LIST OF TABLES AND FIGURES}

Table

I Storage of Uranium(IV) Nitrate Solutions in Glass Bottles 8

\section{Figure}

1 Rate of Reduction of Uranium(VI) to Uranium(IV) in Sulfuric Acid

2 Rate of Oxidation of Uranium(IV) in NItric Acid 


\section{PREPARATION OF URANIUM(IV) NITRATE SOLUTIONS}

\section{INTRODUCTION}

Ferrous sulfamate is used as a reductant for plutonium in the Purex process for the recovery of plutonium and uranium from irradiated natural uranium $(1)$. The ferrous ion is oxidized to the ferric state and the sulfamate ion, in the presence of nitric acid and nitrous acid, decomposes and is oxidized to sulfate, nitric oxide, and nitrogen. The ferric and sulfate ions thus produced are contained in the low activity waste stream. Concentration of this stream by evaporation prior to storage is limited by the presence of salts, primarily ferric sulfate. A considerable saving in storage costs would be realized if ferrous sulfamate were replaced by a reductant that did not contribute to the waste volume.

Uranium(IV) nitrate is a possible attractive reductant in place of ferrous sulfamate for the partitioning of uranium and plutonium. Regnaut, et al.(2) have used uranous sulfate that was prepared by electrolytic reduction in sulfuric acid as a reductant for plutonium in a pilot plant Purex process. Although uranous sulfate was as effective as ferrous sulfamate over a wider range of acid concentrations, uranlum(IV) sulfate would add a significant volume of waste because of the sulfate present. Jenkins and Streeton( 3 ) have considered the use of uranium(IV) in nitrate-sulfamate media and have given some data on uranium distribution for their solvent extraction process. When their stock uranium(IV) sulfamate solutions were diluted with nitric acid to $0.02 \mathrm{M}$ uranium(IV), $0.1 \mathrm{M}$ sulfamic acid, and $0.5 \mathrm{M}$ nitric acid, $4 \%$ of the uranium(IV) concentration was oxidized in 64 hours.

Uranium(IV) has been prepared by the electrolytic reduction of uranyl sulfate ${ }^{(2)}$ and uranyl sulfamate(3). It also has been prepared by photochemical reduction in the presence of water-soluble organic reductants $(4)$, by reduction of uranium(VI) with chromous or titanous ions, or by reduction with any of eight different metals $(5)$. Electrolytic reduction of either uranyl sulfate or sulfamate will produce a reagent that adds to the volume of waste. Photochemical reduction was not successful in producing either rapid or quantitative reducticn to uranium(IV). In nitrate systems, excessive amounts of chromous or titanous ions are consumed; in a more suitable media, such as sulfuric acid, both the excess reducing agent and its oxidized species would have to be separated from the uranium(IV) produced.

Reduction of uranium(VI) to uranium(IV) with zinc or lead in sulfuric acid, as commonly used in analyses with the Jones reductor, followed by conversion of the uranium(IV) sulfate to nitrate, was selected as a potentially simple method of preparation.

Since this work was started Hanford has reported on a similar approach to this method of preparation. $(6)$ 


\section{SUMMARY}

A simple method was developed for the preparation of uranium(IV) at a yield of $98 \%$ in nitric acid solution. Uranium(VI) in IM sulfuric acid was reduced with granulated zinc and the uranium(IV) was precipitated as the hydrated oxide with sodium or ammonium hydroxide. The hydrated oxide of uranium was dissolved in nitric acid that contained hydrazine as a holding reductant. The product solutions were suitable for testing as an alternative for ferrous sulfamate reductant in the Purex process.

\section{DISCUSSION}

\section{REDUCTION}

Sulfuric acid was chosen as a suitable media for the reduction of uranyl ion. Hydrochloric acid was unsatisfactory because of the possibility that chloride 1 on would be present in the final product and would attack mixer-settler equipment. Direct reduction of uranium(VI) in a nitric acid - hydrazine media is impractical because the reaction between zinc and nitrate would rapidly consume the hydrazine. This method of preparation would also require the removal of zinc ions from the uranium(IV) solution to avoid addition of solids to the waste str am.

The simplest method of reduction is the addition of a relatively inexpensive metal to a stirred solution. The metals most commonly used for uranyl ion reduction are usually amalgamated for more rapid reduction, (5) but mercury ions would be difficult to remove from the product uranium(IV) solution. Among the metals, only lead and zinc are inexpensive and effective reductants in the absence of mercury. These metals have the added advantage that their amphoteric properties permit them to be readily separated from the uranium(IV) oxide hydrate.

For milligram quantities, the reduction of uranium(VI) to uranium(IV) in sulfuric acid with a lead reductor was rapid and quantitative; however, for larger quantities of uranium the metal surfaces became coated and the column became ineffective.

Reduction of uranium(VI) to uranium(IV) in sulfuric acid media with untreated zinc metal was rapid. The reductions were performed on solutions that were prepared by dissolving uranium oxide from the Savannah River Plant in dilute sulfuric acid until a concentration of $0.5 \mathrm{M}$ uranium was obtained. Rates of reduction are shown graphically in Figure 1. In each case, 13 grams of uranium were reduced with a $50 \%$ stoichiometric excess of zinc added to a stirred solution. 


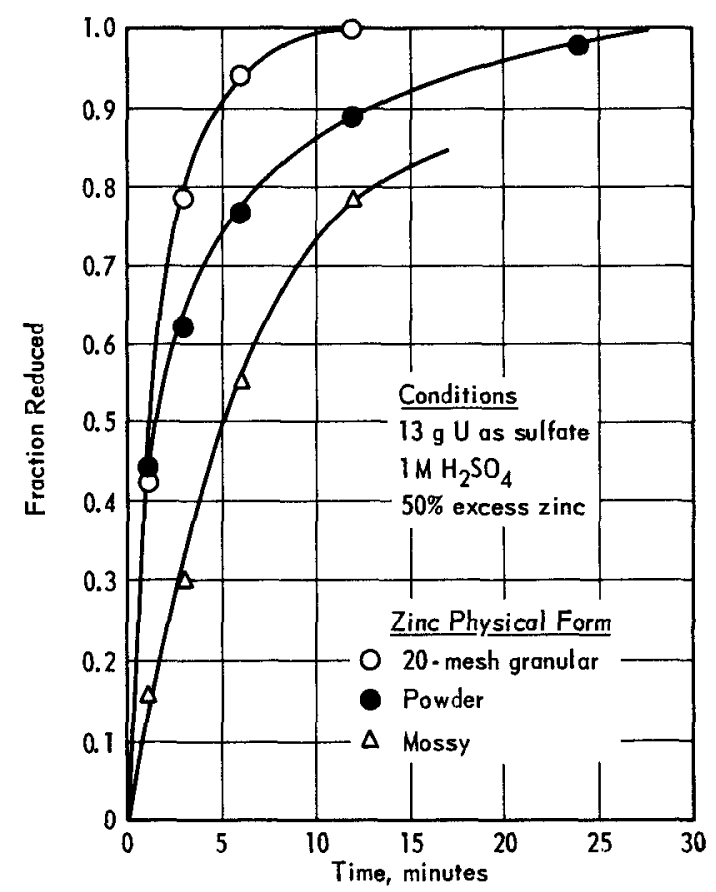

FIG. I RATE OF REDUCTION OF URANIUM (VI) TO URANIUM (IV) IN SULFURIC ACID

Reduction of uranium(VI) was $>99 \%$ complete for granular and powdered zinc in <30 minutes (F1gure 1). Reduction with mossy zinc was slower. The initial reaction with zinc powder was the most rapid, but after I minute of reaction, the powder began to agglomerate and the reaction rate decreased.

The optimum acidity of the solution of uranyl sulfate was I to $3 M$. Above this upper limit, more than a 50\% stoichiometric excess of zinc had to be added to obtain complete reduction to uranium(IV). Also, the solution became heated to $>100^{\circ} \mathrm{C}$ because of the exothermic dissolution of zinc. High final acid concentrations increased the rate of air oxidation of a uranium(IV) solution. Too low an initial acid concentration resulted in incomplete reduction.

From the above information, conditions were selected for a reduction that was performed with one mol of uranium. A $50 \%$ stoichiometric excess of granular zinc was added rapidly to a stirred solution $0.5 \mathrm{M}$ in uranium sulfate and IM in sulfuric acid. Reduction of the uranium(VI) to uranium(IV) was complete in 21 minutes. The final sulfuric acid concentration was $0.4 \mathrm{M}$. 
Solutions of uranium(IV) in 0.1 to $0.5 \mathrm{M}$ sulfuric acla have $<2 \%$ of the uranium oxidized to uranium(VI) over a perlod of 24 hours when the solutions were maintalned at 20 to $25^{\circ} \mathrm{C}$ in an Erlenmeyer flask open to the air. This observation was in agreement with data previousiy reported. (7) The stability of these solutions was due to the low acid concentration and the presence of uranium(IV) sulfate complexes. (8)

\section{SEPARATION}

Uranium(IV) was precipitated by adding the sulfate solution to an excess of either IM ammonium hydroxide or IM sodium hydroxide. The choice of base had no effect on the appearance or filtering characteristics of the precipitate, but sodium hydroxide precipitated zinc when the hydroxyl ion concentration was reduced to 0.2M. However, ammonium hydroxide at a concentration of $0.2 \mathrm{M}$ did not precipitate zinc because of the formation of a zinc ammonia complex.

The hydrated uranium(IV) oxide preclpitate, $\mathrm{UO}_{2} \cdot 2 \mathrm{H}_{2} \mathrm{O}^{(\theta)}$, was initially light green and gelatinous; then it gradually became dark green. When the precipitate was washed with water to remove excess base and sulfate salts, its color changed to a dark gray-green. The precipitate of $\mathrm{UO}_{2} \cdot 2 \mathrm{H}_{2} \mathrm{O}$ oxidized readily in air. After filtering and washing, attempts to dry the precipitate either by heating 1 it in an oven or washing it with alcohol and drying it under vacuum caused 52\% of the uranium(IV) to be oxidized. The color of the precipitate after elther of these treatments was gray.

The washed precipitate dissolved rapidly and completely in dilute solutions of sulfuric, nitric, or hydrochloric acids. Oxidation of the uranium(IV) was very rapid in all concentrations of nitric acid. To prevent this rapid oxidation, various concentrations of hydrazine were used as a holding reductant. The hydrazine was added to the nitric acid prior to the dissolution of the $\mathrm{UO}_{2} \cdot 2 \mathrm{H}_{2} \mathrm{O}$. After the dissolution in nitric acid the uranium(VI) concentration was <2\%.

\section{STABILITY OF SOLUTIONS}

Three solutions of uranium(IV) nitrate with different nitric acid and hydrazine concentrations, were tested for stability. The solutions were stored both in brown and clear glass bottles. Table I gives the test data.

Although the exclusion of light by the brown glass container had little or no influence on the stability of the uranium(IV) in solution C, an average loss of $33 \%$ of the uranium(IV) in solutions $A$ and $B$ occurred in the clear glass bottles. Thus it appears to be desirable to store the solutions of uranium(IV) in opaque containers. 


\section{TABLE I}

Storage of Uranium(IV) Nitrate Solutions in Glass Bottles

\begin{tabular}{|c|c|c|c|c|c|c|}
\hline \multirow[b]{2}{*}{ Solution } & \multicolumn{4}{|c|}{ Initial Composition } & \multicolumn{2}{|c|}{ after 14 Days } \\
\hline & $\begin{array}{l}\mathrm{HNO}_{3}, \\
\mathrm{M} \\
\end{array}$ & $\begin{array}{c}\mathrm{N}_{2} \mathrm{H}_{4}, \\
\mathrm{M}\end{array}$ & $\begin{array}{c}\text { Total U, } \\
\mathrm{M} \\
\end{array}$ & $\begin{array}{c}\vec{U}(I V), \\
M\end{array}$ & $\begin{array}{l}\bar{U}(\text { IV }) \text { in Brown } \\
\text { Bottles, } \mathrm{M}\end{array}$ & $\begin{array}{c}\mathrm{U}(\mathrm{I} V) \text { in Clear } \\
\text { Bottles, } \mathrm{M}\end{array}$ \\
\hline A & 0.5 & 0.2 & 0.25 & 0.22 & 0.20 & 0.13 \\
\hline B & 0.8 & 0.1 & 0.16 & 0.13 & 0.13 & 0.10 \\
\hline $\mathrm{C}$ & 0.9 & 0.02 & 0.17 & 0.13 & 0.12 & 0.12 \\
\hline
\end{tabular}

U(IV) Concentration

The concentration of hydrazine as a holding reductant did not appear to be critical if the solution was not exposed to light during storage. Since $0.02 \mathrm{M}$ hydrazine appears to be adequate in a solution that is approximately $1 \mathrm{M}$ in nitric acid, this concentration was chosen as a lower limit. When the solution is to be stored for longer than two weeks, the hydrazine concentration should be increased to about 0.IM.

The oxidation of uranium(IV) was determined periodically in one solution typical of that which would be sultable for plant tests. The initial concentrations were: $U$ (total), $34.6 \mathrm{~g} / \mathrm{I}$ as the nitrate; $\mathrm{HNO}_{3}, 0.63 \mathrm{M} ; \mathrm{N}_{2} \mathrm{H}_{4}, 0 . I \mathrm{M} ; U(\mathrm{IV}), 30.5 \mathrm{~g} / \mathrm{I}$. During a period of 90 days the solution was stored in a brown bottle on a laboratory bench top, and the uranium(IV) concentration was analyzed four times. The hydrazine was also determined, and the concentration was increased as needed so that it varied from 0.04 to $0.19 \mathrm{M}$.

Figure 2 shows that the decrease in uranium(IV) concentration was linear and, under the above conditions, was $0.5 \%$ per day. This value is in agreement with the data presented in the table that shows an average decrease of $6 \%$ in the uranium(IV) concentration over a period of 14 days, or $0.43 \%$ per day.

The decrease in hydrazine concentration was rather erratic. However, to maintain the initial hydrazine concentration of $0.1 \mathrm{M}, 0.05$ mol of hydrazine had to be added every 30 days to each liter of uranium(IV) nitrate solution.

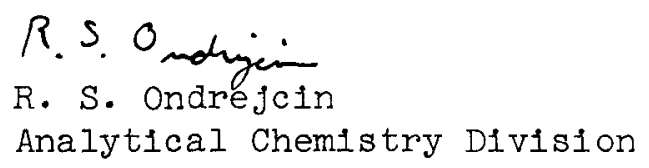




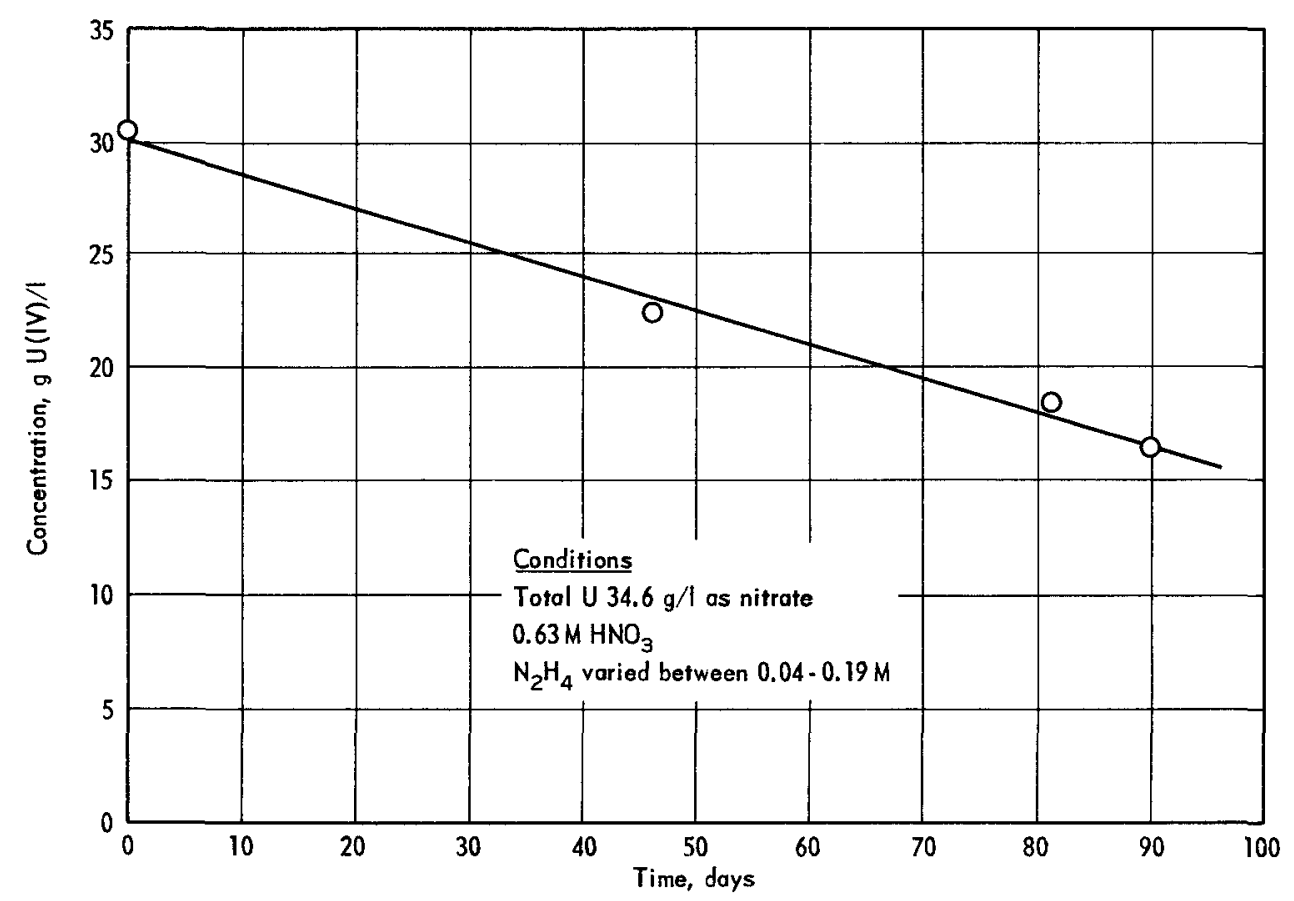

FIG. 2 RATE OF OXIDATION OF URANIUM (IV) IN NITRIC ACID 


\section{BIBLIOGRAPHY}

1. Irish, E. R. Description of the Purex Plant Process. General Electric Company, Hanford Atomic Products Operation, Richland Wash. AEC Research and Development Report HW-60116, 16 pp. (April 1959)(declassified May 19, 1959).

2. Regnaut, P., et al. "The Processing of Irradiated Uranium in the Fontenay-aux-Roses Pllot Plant". Proc. U. N. Intern. Conf. Peaceful Uses Atomic Energy. 2nd, Geneva, 17, 73-95 (1958) P/1172.

3. Jenkins, E. N. and R. J. W. Streeton, The Use of Uranlum IV as a Reagent in the Aqueous Processing of Irradiated Uranium. United Kingdom Atomic Energy Authority. Research Group, Atomic Energy Research Establishment, Harwell, Berkshire, England, Research and Development Report AERE-R3158, $22 \mathrm{pp}$. (December 1959).

4. Williams, C. Progress Report Nuclear Engineering Department. Brookhaven National Laboratory, Associated Universities, Inc. Upton, N. Y. AEC Research and Development Report BNL-618 (S-55), 85 pp. (January - April 1960).

5. Rodden, C. J. Analytical Chemistry of the Manhattan Project. National Nuclear Energy Series, NNES VIII-I, New York: McGrawHill, pp. 54-64 (1950).

6. Bupp, L. P. Chemical Research and Development Report for April 1960, General Electric Company, Hanford Atomic Products Operation, Richland, Washington, AEC Research and Development Report HW-64898 C, 25 pp. (May 13, 1960)(Secret).

7. Lundell, G. E. F., and H. B. Knowles. "The Determination of Uranium". J. Am. Chem. Soc. 47, No. 11, 2637-44 (1925).

8. Mellor, J. W. A Comprehensive Treatise on Inorganic and Theoretical Chemistry. Vol. XII. New York: Longmans, Green and Co. p. 99 (1947).

9. Latimer, W. M. and J. H. Hildebrand, Reference Book of Inorganic Chemistry. 3rd Ed. New York: MacMillan Co., p. 473, (1951). 